\title{
VIBRACIONI TRENING CIJELOG TIJELA POBOLJŠAVA SNAGU MIŠIĆA KOD REKREATIVNO AKTIVNE POPULACIJE
}

\author{
Adam Hawkey ${ }^{1}$ \\ ${ }^{1}$ Istraživački centar za sport, vježbanje i trening, Univerzitet u Vulverhemptonu, \\ Ujedinjeno Kraljevstvo
}

\section{SAŽETAK}

Vibracioni trening cijelog tijela pokazao je poboljšanje sportskih sposobnosti. Međutim, većina istraživanja relativno su koristila intenzivne programe treninga. Ovo straživanje procijenilo je efekat šestonedeljnog programa vibracionog treninga na rekreativno aktivnom stanovništvu. Nakon što je dobijeno etičko instituconalno odobrenje, 22-oje rekretaivno zdravih muškaraca nasumično je regrutovano i podijeljenjo na vibracionu grupu $(n=11)$ i kontrolnu grupu $(n=11)$. Sa vibracionom grupom odrađen je šestonedeljni trening jednom sedmično koristeći tri različite vježbe čučnja $\left(120^{\circ}\right.$ i $90^{\circ}$ statički čučanj i $120^{\circ}-90^{\circ}$ dinamički čučanj) na NEMES Bosco vibracionoj platformi: prva sedmica (3 x 60 s, $35 \mathrm{~Hz} / 2 \mathrm{~mm})$, druga sedmica $(3 \times 70 \mathrm{~s}, 35 \mathrm{~Hz} / 2 \mathrm{~mm})$, treća sedmica $(3 \times 60 \mathrm{~s}, 40 \mathrm{~Hz} / 2 \mathrm{~mm})$, četvrta sedmica $(3 \times 70 \mathrm{~s}, 40 \mathrm{~Hz} / 2 \mathrm{~mm})$, peta sedmica $(3 \times 60 \mathrm{~s}, 45 \mathrm{~Hz} / 2 \mathrm{~mm})$ i šesta sedmica $(3 \times 70 \mathrm{~s}, 45$ $\mathrm{Hz} / 2 \mathrm{~mm})$. Kontrolna grupa koristila je isti program treninga sa lažnom vibracijom $(0 \mathrm{~Hz} / 0 \mathrm{~mm})$. Prije i po završetku istraživanja svi učesnici izvodili su tri maksimalna skoka za procjenu mišićne snage (countermovement skoka). Dvostruka ANOVA s ponovljenim mjerenjem, s jednim među-faktorom "grupa" (eksperimentalna nasuprot kontrolna) i jednim unutrašnjim faktorom "vrijeme" (prije i poslije istraživanja) pokazala su da postoji statistički značajna vrijeme x grupa interakcija $(p<0,0001)$ kod izvođenja countermovement skoka između eksperimentalne (prije - 0,43 $\pm 0,08 \mathrm{~m}$ i poslije - $0,49 \mathrm{~m}$ $\pm 0,08)$ i kontrolne grupe (prije - 0,43 $\pm 0,07 \mathrm{~m}$ i poslije - 0,41 $\pm 0,08 \mathrm{~m}$ ). Rezultati pokazuju da šestonedeljni vibracioni trening provođen jedan puta nedeljno je dovoljan da izazove značajno povećanje preformansi skoka kod rekreativno aktivnog stanovništva

Ključne riječi: skokovi, performanse, čučnjevi, rekreativno aktivni, snaga, sila.

\section{UVOD}

Vibracija se može opisati kao mehanički stimulans koji karakteriše ponavljanje oscililatornog kretanja naprijed nazad po istom obrazcu. Mi doživljavamo vibracije u svakodnevnom životu kada se vozimo automobilom ili na industrijskim mašinama sa motorizovanim dijelovima. Izloženost vibracijama je tradicionalno povezana sa negativnim efektima na ljudsko tijelo. Međutim trening vibracije cijelog tijela (WBV) koji se takođe naziva i vibracioni tening (VT) ili vibraciono vježbanje (VE), je relativno nedavno razvijen u svrhu unapređenja zdravlja i kondicije. Najčešći način primjene vibracija, kao sepcifičan vid treninga, je korišćenjem vibracione platforme, takođe poznate kao vibraciona ploča (Slika 1). Ove platforme rade pokretima koji mogu da budu klasifikovani kao linerani (samo vertikalno), oscilatorni (vertikalno kretanje sa svakim sledećim na drugoj strani po sistemu klackalice) i triplanarni (kretanje kroz sve tri ose), a intenzitetom treninga se rukovodi promjenom frekvencije i/ili amplitude oscilacija (Hawkey, 2012). Frekvencija vibracionih podsticaja jednostavno kvantifikuje broj impulsa ili oscilacija $(\mathrm{Hz})$ isporučenih svake sekunde (ponavljanje stope ciklusa) dok amplituda odgovara obimu vertiklanog pomaka iz centralne tačke kretanja ili njenog ravnotežnog polažaja (Riley i Sturges, 1996). Ubrzanje kretanja mjeri se u g-oima, ili magnutudi gravitacije (gdje je $1 \mathrm{~g}$ ubrzanje zbog gravitacionog zemljinog polja ili 9,81 $\mathrm{ms}^{-2}$ ). Ubrzanje 
koje tijelo doživljava dok je na vibracionoj platformi može se procijeniti korišćenjem formule prikazane na Slici 2 (Gdje je iskustveno ubrzanje izraženo kao ekvivalent ubrzanja zemljine gravitacije [9.81 $\left.\mathrm{ms}^{-2}\right]$; A je amplituda vibracije; a $f$ je frekvencija vibracije). Za ovu formulu, da bi efikasno djelovala, od presudnog značaja je da se smanje sve komponente mase, dužine i vremena, tako da sila $=$ masa $\times$ dužina $\times$ vrijeme $^{-2}$ (Hawkey, 2012).

Iako tačni mehanizmi još nisu u potpunosti razumljivi, smatra se da WBV izaziva promjene kroz fiziološke adapatacije prilagođavanja vibracionim talasima (Cardinale i Bosco, 2003), putem procesa nazvanog tonik vibracioni refleks (TVR; Nordlund i Thorstensson, 2007), koji su prvobitno predložili Eklund i Hagbarth (1966) nakon istraživanja direktng izlaganja tetiva na vibracije. Vjeruje se da stimulacija neuromišićnih puteva i mišićnog vretena (Ia. afferent) pobuđuje motorne neurone što izaiziva kontrakcije istoimenih motornih jedinica (Luo, McNamara i Moran, 2005), što, prema Mester, Kleinoder i Yue (2006), znači da TVR može poboljšati makasimlanu voljnu kontrakciju mišića. Ipak, veza između WBV i TVR nije u potpunosti prihvaćena, s drugim prijedlozima alternativnih mehanizama povećanja mišićne tempereture i protoka krvi (Issurin i Tenenbaum, 1999), promjene percepcije vibracijom (Liebermann i Issurin, 1997), povećanja sekrecije hormona (Cardinale i Bosco, 2003) i sinhronizaciju motornih jedinica i upošljavanje prethodno neaktivnih motornih jedinica (Issurin i Tenenbaum, 1999). Istraživanja su pokazala da izvođenje tradicionalnog treninga sa tegovima na vibracionoj platformi daje značajno veća poboljšanja maksimalne i eksplozivne snage u odnosu na tradicionalne trenige sa tegovima (Ronnestad, 2004), dok je povećanje stope sile razvoja i smanjenje elektromehanićkih kašnjenja i djelotvornost eksplozivne mišićne aktivacije takođe uočen (Hong, Kipp, Maddalozzo i Hoffman, 2010).

Stoga se vibracioni trening koristi u različite namjene i u medicinskom i u sportskom polju. Uočena su poboljšanja zdravlja kostiju kod žena u postmenopauzi (Rubin i saradnici, 2004), ravnoteže, hoda i procjena kvaliteta života starijih osoba (Bruyere i saradnici, 2005) i smanjenje otoka zglobova kod pacijenata sa rematoidnim artritisom (Kumari, Wyon, Hawkey i Metsios, 2011), dok je skočnost kod poluprofesionalnih fudbalera (Hawkey, Evans i Nevill, 2012), profesionalnih fudbalskih golmana (Hawkey, Morrison, Williams i Nevill, 2009a) i brzina, skok u vis i izdržljivost u eksplozivnoj snazi sprtista (Paradisis i Zacharogiannis, 2007) sve bilo poboljšano WBV programima. Ipak, u svim istraživanjima nije došlo do takvih poboljšanja. Jedna studija, sprovedena na košarašima, nije prijavila nikava poboljšanja u preformansama skoka nakon izlaganja WBV (Hawkey, Lau i Nevill, 2009b). Razlozi za ove razlike mogu da budu multifaktorijalne: različiti protokoli, oprema za testiranje i nivo vještine i iskustva učesnika. Dok su većina prethodnih istraživanja govorila o poboljšanju skakačkih kvaliteta kod populacije u treningu, ona sprovedena na fizički neaktivnim ili rekretaivno aktivnim pojedincima su ograničena. Torvinen, Kannu i Sievanen (2002) našli su poboljšanje od 8,5\% nakon četiri mjeseca treninga kod netreniranih osoba. Nažalost, nije koišćena placebo grupa što otežava da se utvrdi da li su poboljšanja rezultat vježbi koje su rađene na platformi ili od WBV djelovanja. Delecluse, Roelants i Verschueren (2003) uključili su kontrolnu grupu i prijavili su skoro $17 \%$ poboljšanja u snazi ekstenzora koljena i skoro $8 \%$ povećanja u skakačkim performansama kod osoba sa smanjenom fitzičkom aktivnošću koji su uključeni u WBV trenining program obuke tri puta sedmično u trajanju tokom dvanaest nedjelja. Istraživanja pokazuju povećanje popularnosti i dostupnosti vibracionih platformi u fitnes centrima i dvoranama širom svijeta (Fischbach, 2007) takao da postoji potreba daljih dodatnih istraživanja na ograničen broj raspoloživih podataka o efektima WBV treninga na rekretaivno aktivnu populaciju. Dakle, cilj ovog istraživanja bio je da se ispita uticaj relativno kratkog trajanja, niskog intenziteta WBV trening programa na skakčke performance rekretaivno aktivne populacije.

\section{METODE}

Nakon etičkog institucionalnog odobrenja i popunjavanja informativnog pristanka i medicinskog upitnika, 22-oje zdravih, rekreativno aktivnih, redovnih studenata sportista muškog pola (prosječna starost $28, \mathrm{~s}=10$ godina; prosječna visina $1,77, \mathrm{~s}=0,10 \mathrm{~m}$; prosječna težina $77, \mathrm{~s}=13 \mathrm{~kg}$ ) su nasumično izabrani za WBV i kontrolnu grupu. Vibraciono djelovanje sastojalo se u šetonedjeljnom WBV treningu koristeči tri različite vježbe čučnja $\left(120^{\circ}\right.$ i $90^{\circ}$ statički čučanj i $120^{\circ}-90^{\circ}$ dinamički čučanj, praćen pomoću goniometra) sprovedenom jednom nedeljno na NEMES Bosco vibracionoj platformi (Slika 1). Prije treninga i testiranja i vibraciona i kontrolna grupa izvodili su petominutno zagrijavanje na Monark Cycle Ergometer sa otkucajima srca 120-140 BPM u skladu sa American College of Sports Medicine (ACSM) koji preporučuje minimalno pet do deset minuta niskog do umjerenog nivoa aktivnosti u cilju povećanja temperature mišića (ACSM, 2012). Trening se pridržavao sledećih principa opterečenja: 3 x 60 s (1 x 60 s za svaku vježbu, sa 30 s odmora između njih) sa frekvencijom od $35 \mathrm{~Hz}$ i 


\section{SLIKA 1}

Trening sportiste na NEMES Bosco vibracionoj platformi (C) Adam Hawkey).

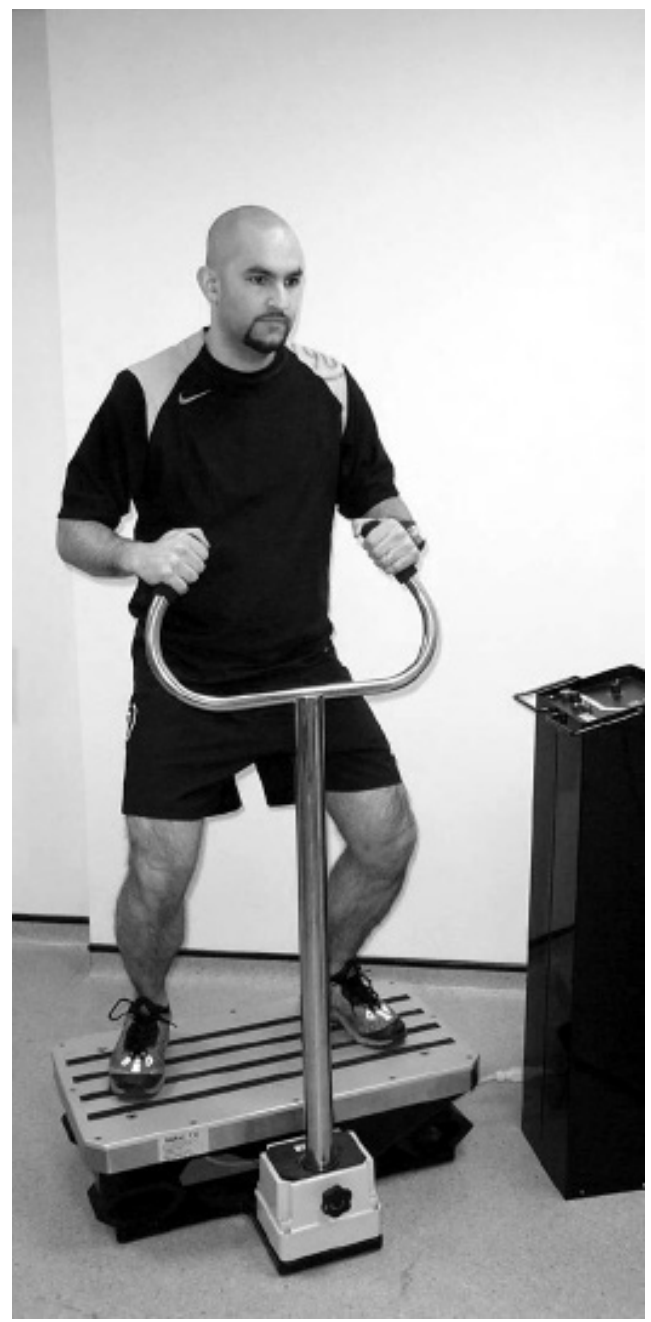

amplitudom $2 \mathrm{~mm}$ (ubrzanje $=9,86 \mathrm{~g}$ ) u prvoj sedmici; 3 x 70 s sa $35 \mathrm{~Hz} / 2 \mathrm{~mm}$ u drugoj sedmici; 3 x $60 \mathrm{~s}$ sa $40 \mathrm{~Hz} / 2 \mathrm{~mm}(\sim 12.9 \mathrm{~g})$ u trećoj sedmici; 3 x 70s sa $40 \mathrm{~Hz} / 2 \mathrm{~mm}(\sim 12.9 \mathrm{~g})$ u četvrtoj sedmici; 3 x $60 \mathrm{~s} \mathrm{sa}$ $45 \mathrm{~Hz} / 2 \mathrm{~mm}(\sim 16.3 \mathrm{~g})$ u petoj sedmici; i 3 x $70 \mathrm{~s} \mathrm{sa}$ $45 \mathrm{~Hz} / 2 \mathrm{~mm}(\sim 16.3 \mathrm{~g})$ u šestoj sedmici. Protokol je tako izabran da podržava prethodna istraživanja koja su pokazala da frekvencije između $35 \mathrm{~Hz}$ i $50 \mathrm{~Hz}$ mogu da unaprijede skakačke preformanse kod netreniranih (Bazett-Jones, Finch i Dugan, 2008; Delecluse i saradnici, 2003) i treniranih osoba (Hawkey i saradnici, 2009a). Vibraciono ubrzanje izračunato je shodno Hawkey (2012) (Slika 2).

Prije i po završetku istraživanja svi učesnici izvodili su tri maksimalna countermovemnt skoka (CMJ) koji su se pokazali tačnom i pouzdanom metodom procjene tjelesne veličine nezavisne mišićne snage (Marković $i$ Jarić, 2007). Svi skokovi vršeni su na kontakt prostirci (Just Jump: Probotics Inc. USA) koristeći brojne prethodne studije (Christensen i Nordstrom, 2008; Delecluse i saradnici, 2003; Hawkey i saradnici, 2012) koji se pokazao kao pouzdan metod za procjenjivanje skakačkih performansi (Isaacs, 1998) sa visokim kriterijumom valjanosti (Leard i saradnici, 2007). Tokom testiranja skoka ruke su morale da ostanu na kukovima u skladu sa prethodnim istraživanjima (Hawkey i saradnici, 2012; Linthorne, 2001) u pokušaju standardizacije skokova pošto upotreba ruku ima značajan uticaj na skakačke pereformanse (Linthorne, 2001). Koljeni uglovi pri skokovima u početku su

\section{SLIKA 2}

Formula koja se koristi za izračunavanje ubrzanja vibracije (prilagodeno od Hawkey, 2012).

$$
a=\frac{A \times(2 \pi f)^{2}}{g}
$$


mjereni goniometrom, a potom su vizuelno kontrolisani da bi se obezbjedila doslijednost. Svi CMJ podaci su analizirani korišćenjem dvostruke ANOVA sa ponovljenim mjerenjima, s jednim među-faktorom "grupa" (eksperimentalna nasuprot kontrolna) i jednim unutrašnjim faktorom "vrijeme" (prije i poslije istraživanja).

\section{REZULTATI}

Dvostruka ANOVA sa ponovljenim mjerenjem pokazala je da postoji statistički značajna vrijeme $\mathrm{x}$ grupa interakcija $(p<0,0001)$ za CMJ preformace tokom istraživanja (prije $0,43 \pm 0,08 \mathrm{~m}$ do poslije $0,49 \mathrm{~m} \pm 0,08)$ i kontrolne grupe (prije $0,43 \pm 0,07 \mathrm{~m}$ do poslije $0,41 \pm 0,08 \mathrm{~m}$ ) (Slika 3).

\section{DISKUSIJA}

Prethodna istraživanja o efektima WBV pokazala su poboljšanja u različitim mjerama uticaja u različitim populacija. Istraživanja sprovedena na fudbalerima i atletičarima (Hawkey i saradnici, 2009a, 2009b; Hawkey i saradnici, 2012; Paradisis i Zachardiogiorgis, 2007)

\section{SLIKA 3}

Grafikon dvosmjerne ANOVA koji pokazuje sposobnost skoka prije i poslije vibracionog treninga eksperimentalne $i$ kontrolne grupe

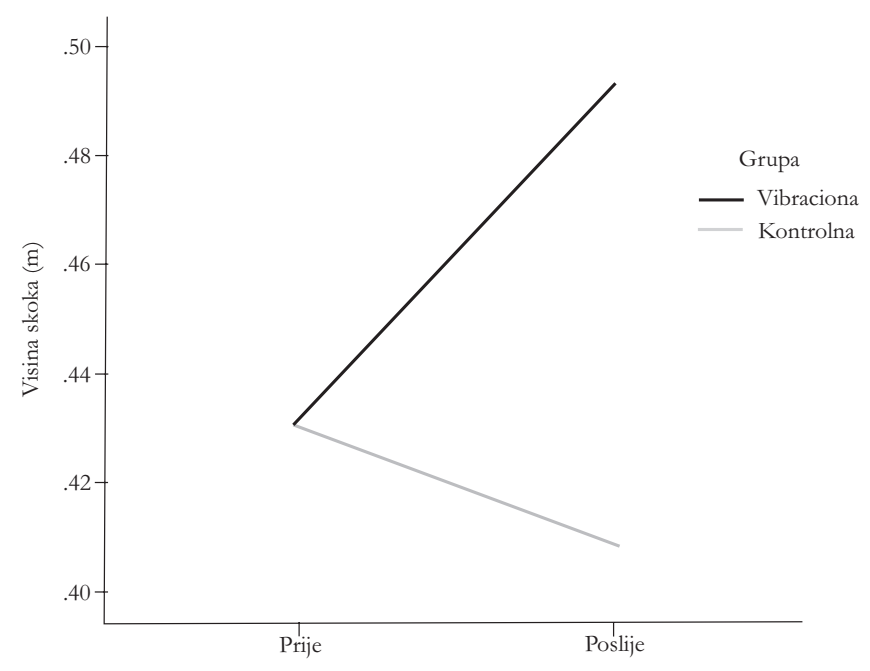

i pojedincima koji se ne bave fizičkom aktivnošću (Delecluse i saradnici, 2003; Torvinen i saradnici, 2002) su istakla da WBV ima mogućnost da unaprijedi specifične performnse. Rezultati ovog istraživanja su pokazala da šestomedjelnji WBV trening je dovoljan da dovede do značajnih poboljšanja performansi vertikalne skočnosti kod rekretaivno aktivne muške populacije.Razlika između prije i poslije istraživanja skakačkih performansi WBV grupe jednaka je a > $14 \%$ poboljšanja, dok je kontrolna grupa doživjela $3 \%$ smanjenje u prije i poslije mjerenju što je rezultiralo stratistiki značajnom interakcijom vrijeme $\mathrm{x}$ grupa $(p$ $<0,0001)$.Uprkos činjenici što je ovo istraživanje sprovedeno u periodu od šest nedjelja rezultati pokazuju sličnost sa istraživanjima Delecluse i saradnika (2003) and Torvinen i saradnika (2002) koji su porvednea u periodu od 12 sedmica odnosno 4 mjeseca. Ipak je teško porediti ova istraživanja zbog razlike u eksperimentalnim protokolima, korištenja različite opreme i za trening i za testiranje i nivoa vještine i iskustva učesnika. To su naglasili Moras, Tous, Muñoz,
Padullés i Vallejo (2006) koji navode da razlike njihovih rezultata kada se uporede sa drugim sličnim istraživanjima su zbog različite opreme (NEMES versus PowerPlate) ili različitog uzorka uključenih u odgovarajuće istraživanje. Jedna od razlika u protokolu je da Delecluse i saradnici (2003) koriste samo ženske učesnike dok ovo istraživanje koristi isključivo mušku populaciju. Ovo je potencijalno značajno zato što, prema Bazett-Jones i saradnici (2008), muškarci i žene različito reaguju na vibracione nadražaje. Ovdje je i očigledna razlika u frekvenciji i amplitudi platforme koja se koristila u ovom istraživanju u odnosu na neka prethodna istraživanja. Iako je opširno objašnjeno da frekvencija od $30 \mathrm{~Hz}$ je pogodna za poboljšanje mičićne snage (Paradisis i Zachardiogiorgis, 2007) nejasno je zašto je to tako i trenutno postoji konfuzija o tome kako su koje varijable korišćene u vibracionom treningu (frekvencija, amplituda i ubrzanje) i izvještavanju i kvantifikovanju (Hawkey, 2012; Lorenzen, Maschette, Koh i Wilson, 2009). Opravdanje za korištenje frekvencije u rasponu 35-45 Hz i amplitude $2 \mathrm{~mm}$ je u skladu sa prethodnim israživanjima (Delecluse 
i saradnici, 2003; Hawkey i saradnici, 2009a, 2009b; Hawkey i saradnici, 2012) koji su prijavili poboljšanje u skakačkim performansama unutar ovog raspona. Vježbe čučnjeva $\left(90^{\circ}-120^{\circ}\right)$ korišćene u ovom istraživanju su u skladu sa prethodnim istraživanjima i pokazale su dobre rezultate u skakačkim performansama (Hawkey i saradnici, 2012; Paradisis i Zachardiogiorgis, 2007).

Takođe je teško kvantifikovati mehanizme uključene u prijavljenim poboljšanjima performansi. Poboljšanja u mišićnom učinku koja su proizašla nakon WBV treninga slična su onim koja se mogu vidjeti nakon treninga eksplozivne snage (Bosco, Colli i Introini, 1999). Neuronski mehanizam je prvi koji je uključen u adaptaciju skeletnih mišića (Delecluse i saradnici, 2003) stoge je vjerovatno da poboljšanja u preformansama, o kojima se govori nakon WBV treninga, takođe vjerovatno dolaze od neuronskih adaptacija. Mehanizmi ovih prilagođavanja su vjerovatno su u stimulisanju primarnih završetaka mišićnog vretena što rezultira toničkim kontrakcijama mišića poznat kao tonički vibracioni refleks (Mester i saradnici, 2006), povećava sinhonizaciju motornih jedinica, kontrakcije mišića sinergista i povećava inhibiciju mišića anatagonista (Hawkey, 2012). Moguće je ukazati da poboljšanja mišićne snage u dvanaestonedjeljnim (Delecluse i saradnici, 2003) i četvoromjesečnim (Torvinen i saradnici, 2002) istraživanjima nisu samo pod uticajem nervnih adpatacija (kao što je prethodno naglašeno) već $i$ kroz intramuskularne faktore kao što su proširenja sporih i brzo trzajnih vlakana, kao što je ustanovljeno u istraživanjima u kojima su vibraciji bili izloženi štakori (Necking, Lundstrom, Lundborg, Thornell i Friden, 2006).

Rezultati ovog istraživanja idu u prilog sve većem broju dokaza o prednosti vibracijskog treninga na niz izmjerenih performansi na različite populacije. $U$ kombinaciji sa nalazima istraživanja Delecluse i saradnika (2003) i Torvinen i saradnika (2002) i, naročito, ovog istraživanja rezultati su ohrabrujući za sedentarne ili fizički neaktivne pojedince koji žele da poboljšaju svoju mišićnu snagu sa relativno malim angažovanjem, uticajem vježbi niskog intenziteta. Međutim, postoje i neka ograničenja u aktuelnom istraživanju. Iako je istraživanje veoma dobro kontrolisano što se tiče standardizacije protokola treninga kao i nivoa sposobnosti pojedinaca nije bilo regulisanja aktivnosti učesnika izvan okvira istraživanja. Zato je moguće je da su učesnici i kontrolne i WBV grupe radili dodatne treninge tokom istraživanja, a to je moglo da utiče na bolje skakačke performanse WBV grupe ili da dovede u pitanje rezultate kontrolne grupe zbog umora mišića. Stepen ubrzanja koje nije kvantifikovano ili procienjeno korišćenjem akcelerometra, kao što je to bio slučaj u istraživanju Delecluse i saradnika (2003) takođe je negativan aspekt ovog istraživanja.

\section{ZAKLJUČAK}

Rezultati ovog istraživanja pokazuju da šestonedjeljni WBV program treninga, koji se izvodi jedan put sedmično, ima potencijal da staitistički značajno poboljša skakačke preformanse, a samim tim i mišićnu snagu, rekreativno aktivnih muškaraca. Iako rezultati ovog i drugih prethodnih istraživanja govore u prilog uključivanja vibracionog treninga za čitav niz zdravstvenih, kondicionih i poboljšanja preformansi trenutno su nejasni precizni mehanizmi koji utiču na te pogodnosti i potencijalni uticaj, ako postoji, svakog dodatnog treninga koji se izvodi izvan djelokruga i kontrole ovog istraživanja. Buduća istraživanja trebala bi da se fokusiraju na utvrdivanje optimalnih frekvencija i amplituda pogodnih za maksimalno poboljšanje preformansi. Bilo bi korisno u daljim istraživanjima usmjeriti se na uticaj nivoa aktivnost/ učinak, trajanje i specifičnost vježbi koje se izvode na vibracionoj platformi kao i na razlike u polu i godinama starosti.

\section{LITERATURA}

Bazett-Jones, D. M., Finch, H. W., \& Dugan, A. L. (2008). Comparing the effects of various wholebody vibration accelerations on countermovement jump performance. Journal of Sports Science and Medicine, 7, 144-150.

Bosco, C., Colli, R., \& Introini, E. (1999). Adaptive responses of human skeletal muscle to vibration exposure. Clinical Physiology, 19, 183-187. doi: 10.1046/j.1365-2281.1999.00155.x; PMid: 10200901

Bruyere, O., Wuidart, M. A., Di Palma, E., Gourlay, M., Ethgen, O., Richy, F., \& Reginster, J. Y. (2005). Controlled whole body vibration to decrease fall risk and improve health-related quality of life of nursing home residents. Archives of Physical Medicine and Rehabilitation, 86(2), 303-307. doi: 10.1016/j. apmr.2004.05.019; PMid: 15706558

Cardinale, M., \& Bosco, C. (2003). The use of vibration as an exercise intervention. Exercise and Sport Science Reviews, 31, 3-7. doi: 10.1097/ 00003677-200301000-00002

Delecluse, C., Roelants, M., \& Verschueren, S. (2003). Strength increase after whole-body 
vibration compared with resistance training. Medicine and Science in Sport and Exercise, 35, 1003-1041. doi: 10.1249/01.MSS.0000069752. 96438.B0; PMid: 12783053

Eklund, G., \& Hagbarth, K. E. (1966). Normal variability of tonic vibration reflex. Experimental Neurology, 16, 80-92. doi: 10.1016/00144886(66) 90088-4

Fischbach, A. (2007). Shaky ground. Fitness Business, Pro, October Issue.

Hawkey, A., Morrison, D., Williams, D., \& Nevill, A. (2009a). Effect of a five-week whole body vibration training programme on vertical jump performance in male professional football goalkeepers. Journal of Sports Sciences, 27(4), S138.

Hawkey, A., Lau, Y., \& Nevill, A. (2009b). Effect of six-week whole body vibration training on vertical jump and flexibility performance in male national league basketball players. Journal of Sport Sciences, 27(4), S138-S139.

Hawkey, A. (2012). Editorial: Quantification, clarification and standardisation of whole body vibration. Journal of Sports Therapy, 5(1), Editorial paper n. p.

Hawkey, A., Evans, R., \& Nevill, A. (2012). Whole body vibration training improves sport specific performance measures in semi-professional footballers. Proceedings of British Association of Sport and Exercise Sciences (BASES) Biomechanics Interest Group Annual Meeting, 27: 30. Retrived from http://www.science.ulster.ac.uk/big2012/ public/pdf/BIG_2012_Proceedings_Ulster.pdf

Hong, J., Kipp, K., Maddalozzo, G., \& Hoffman, M. A. (2010). Acute effects of whole body vibration on rate of force development and electromechanical delay. Journal of Sports Therapy, 3(3), 3-9.

Issurin, V. B., \& Tenenbaum, G. (1999). Acute and residual effects of vibratory stimulation on explosive strength in elite and amateur athletes. Journal of Sports Sciences, 17, 177-82. doi: 10.1080/026404199366073; PMid: 10362384

Kumari, R., Wyon, M., Hawkey, A., \& Metsios, G. (2011). Effects of vibration on disease activity scores in patients with rheumatoid arthritis: a case study. Journal of Sports Therapy, 4(1): 30-33.

Leard, J. S., Cirillo, M. A., Katsnelson, E., Kimiatek, D. A., Miller, T. W., Trebincevic, K., \& Garbalosa, J. C. (2007). Validity of two alternative systems for measuring vertical jump height. Journal of Strength and Conditioning Research, 21(4): 1296-1299. doi: 10.1519/00124278200711000-00055; doi: 10.1519/R-21536.1; PMid: 18076265
Liebermann, D. G., \& Issurin, V. B. (1997). Effort perception during isotonic muscle contractions with superimposed mechanical vibration stimulation. Journal of Human Movements Studies, 32, 171-186.

Linthorne, N. P. (2001). Analysis of standing vertical jumps using a force platform. American Journal of Physics, 69(11), 1198-1204. doi: 10.1119/1.1397460

Lorenzen, C., Maschette, W., Koh, M., \& Wilson, C. (2009). Inconsistent use of terminology in whole body vibration exercise research. Journal of Science and Medicine in Sport, 12, 676-678. doi: 10.1016/j.jsams.2008.06.008; PMid: 18762453

Luo, J., McNamara, B., \& Moran, K. (2005). The use of vibration training to enhance muscle strength and power. Sports Medicine, 35, 23-41. doi: 10.2165/00007256-200535010-00003; PMid: 15651911

Markovic, G., \& Jaric, S. (2007). Is vertical jump height a body size-independent measure of muscle power? Journal of Sports Sciences, 25(12), 1355-1363. doi: 10.1080/02640410601021713; PMid: 17786688

Mester, J., Kleinoder, H., \& Yue, Z. (2006). Vibration training: benefits and risks. Journal of Biomechanics, 39(6), 1056-1065. doi: 10.1016/j. jbiomech.2005.02.015; PMid: 15869759

Moras, G., Tous, J., Muñoz, C. J., Padullés, J. M., \& Vallejo, L. (2006). Electromyographic response during whole-body vibrations of different frequencies with progressive external loads 10(93). Retrived from http://www.efdeportes. com/efd93/emg.htm.

Necking, L. E., Lundstrom, R., Lundborg, G., Thornell, L. E., \& Friden, J. (1996). Skeletal muscle changes after short term vibration. Scandinavian Journal of Plastic and Reconstructive Surgery and Hand Surgery, 30, 99-103. doi: 10.3109/02844319609056390; PMid: 8815978

Nordlund, M. M., \& Thorstensson, A. (2007) Strength training effects of whole-body vibration? Scandinavian Journal of Medicine and Science in Sports, 17, 12-17.

Paradisis, G., \& Zacharogiannis, E. (2007). Effects of whole-body vibration training on sprint running kinematics and explosive strength performance. Journal of Sports Science and Medicine, 6, 44-49.

Riley, W., \& Sturges, L. (1996). Engineering Mechanics: Dynamics. 2nd ed. New York, NY: John Wiley \& Sons, Inc. 
Ronnestad, B. R. (2004). Comparing the performance-enhancing effects of squats on a vibration platform with conventional squats in recreationally resistance-trained men. Journal of Strength and Conditioning Research, 18(4), 839-845. doi: 10.1519/00124278-200411000-00027; doi: 10.1519/14573.1; PMid: 15574092

Rubin, C., Recker, R., Cullen, D., Ryaby, J., McCabe, J., \& McLeod, K. (2004). Prevention of postmenopausal bone loss by a low-magnitude, high-frequency mechanical stimuli: a clinical trial assessing compliance, efficacy and safety. Journal of Bone and Mineral Research, 19(3), 343-351. doi: 10.1359/JBMR.0301251; PMid: 15040821

Torvinen, S., Kannu, P., \& Sievanen, H. (2002). Effect of four-month vertical whole body vibration on performance and balance. Medicine and Science in Sport and Exercise, 34, 1523-1528. doi: 10.1097/00005768-200209000-00020

Primljeno: 11. maja 2012 Izmjene primljene: 1. decembar 2012 Odobreno: 7. decembar 2012

Korespondencija: Mr Adam Hawkey Research Centre for Sport,

Exercise and Performance University of Wolverhampton Gorway Road Walsall

WS1 3BD

Ujedinenjeno Kraljevstvo Telefon: 00441902322824

Fax: 00441902323295

E-mail: A.Hawkey@wlv.ac.uk 